\title{
LEGISLAÇÕES MUNICIPAIS DO RIO GRANDE DO SUL REFERENTES À ARBORIZAÇÃO URBANA - ESTUDO DE CASOS
}

\author{
Flávia Gizele König Brun¹, Regina Hardok Fuchs², Eleandro José Brun³, Luiz Ernani \\ Bonesso de Araújo ${ }^{4}$
}

(recebido em 20.05.2008 e aceito para publicação em 18.09.2008)

\section{RESUMO}

Estudaram-se as legislações municipais relacionadas à arborização urbana em dez municípios do Rio Grande do Sul (RS): Santa Cruz do Sul, Caxias do Sul, São Borja, Pelotas, Giruá, Nonoai, Santo Ângelo, Quinze de Novembro, São Paulo das Missões e Uruguaiana, e sua relação com aspectos do Código Florestal Federal, Código Florestal Estadual/RS, Lei de Crimes Ambientais, Política Nacional do Meio Ambiente, Código do Consumidor e Estatuto das Cidades. Além disso, observaram-se aspectos técnicos recomendados nas legislações municipais quanto à indicação de espécies, implantação, manutenção, avaliação, entre outros aspectos. Dos 10 municípios analisados, 6 apresentavam leis próprias para a arborização urbana e os demais têm a temática inserida na sua política de meio ambiente. Somente um município tem lei incentivando a conservação de áreas verdes particulares. Em poucos, menciona-se a necessidade de programas educativos na arborização. Nos aspectos técnicos, muitas leis municipais apresentam equívocos quanto ao corte, poda, substituição, reposição e espécies exóticas com princípios tóxicos. O direito de acesso à informação pela população também não é garantido em boa parte das leis. Recomenda-se, a nível Federal, a inclusão de um capítulo dentro do Estatuto das Cidades, sobre a arborização urbana, como balizador na elaboração de leis municipais relacionadas.

Palavras-chave: legislação municipal, planejamento urbano, qualidade de vida.

1. Eng. Florestal, M.Sc. Doutoranda em Recursos Florestais - ESALQ/USP. E-mail: fgkbrun@esalq.usp.br.

2. Geógrafa, M.Sc. Especialista em Educação Ambiental. E-mail: reginahardok@yahoo.com.br.

3. Eng. Florestal, Doutor, Professor da UTFPR - Campus Dois Vizinhos. E-mail: eleandrobrun@utfpr.edu.br.

4. Bacharel em Direito, Prof. Dr. do Centro de Ciências Sociais e Humanas - CCSH - UFSM. E-mail: ernani@smail.ufsm.br. 


\title{
MUNICIPAL LEGISLATIONS OF RIO GRANDE DO SUL WITH RELATION THE URBAN TREES - CASES STUDIES
}

\begin{abstract}
The municipal legislations about urban trees in ten cities of the Rio Grande do Sul state (RS) was studied: Santa Cruz do Sul, Caxias do Sul, São Borja, Pelotas, Giruá, Nonoaí, Santo Ângelo, Quinze de Novembro, São Paulo das Missões and Uruguaiana, and its relation with aspects of the Federal Forest Code, State Forest Code/RS, Environmental Crimes Law, Environment National Politics, Consumer Code and Cities Statute. Besides, recommended technician aspects were observed in the municipal laws about to the indication of species, implantation, maintenance, evaluation, among others aspects. Of the 10 analyzed cities, 6 presented specifics laws for the urban trees and in the others, the subject is inserted in its politics of environment. Only one city has law stimulating the conservation of particular green areas. In few, it is mentioned the necessity of educative programs about urban trees. In the technician aspects, many municipal laws present mistakes about the cut, pruning, substitution and exotic species with toxic components. The access to the information to the population is also not guaranteed in most part of the laws. It's recommended, in the Federal level, the inclusion of a chapter inside of the Cities Statute, on the urban trees, as base in the elaboration of related municipal laws.
\end{abstract}

Key-words: municipal legislation, urban planning, life quality.

\section{INTRODUÇÃO}

O ambiente urbano é a resultante das interações dos fatores ambientais, biológicos e sócio-econômicos, onde o meio edificado pelo homem predomina sobre o meio físico causando profundas alterações sobre este e a qualidade de vida dos seres (LOMBARDO, 1990), o que implica em uma perda gradual crescente de sua qualidade de vida.

Portanto, a qualidade de vida nos centros urbanos é representada pela relação entre as construções civis e o espaço viário, isto é, o espaço demandado pela massa de veículos, pessoas e as árvores, etc., onde a arborização integra-se moderando o clima e estabelecendo um relacionamento entre o homem e o ambiente, empregando assim não apenas um papel decorativo, mas um indicador de saúde urbana (TEIXEIRA et al., 2003).

Conforme Lorenzi (1992), a relação das árvores com a população brasileira, em especial, está intimamente ligada à história e ao desenvolvimento econômico-social do país, pois se encontra a relação mais antiga e importante. É como o próprio nome da nação "Brasil", emprestado da árvore "Pau-brasil", que representou o primeiro grande ciclo econômico da história de nosso país. Sendo que dezenas de cidades do país também 
tiveram seus nomes a partir de árvores nativas que eram importantes ou freqüentes em sua região geográfica como: Cedro-SP, Imbuia-SC, Angicos-PB, Castanhal-PA, Juazeiro-BA, entre outras.

Neste sentido, Stringheta (2005) coloca que o ato de arborizar cidades surgiu da necessidade de se manter o vínculo com a natureza, compensando de certa forma as angústias criadas pelas complexidades da civilização moderna, pois a arborização urbana humaniza os espaços das cidades permitindo que se desfrute a denominada "qualidade de vida urbana". Por outro lado, a autora indica que se torna emergente, que se escape das tendências de globalização da sociedade moderna, que homogeneíza conceitos e paisagens.

Porém na maioria das cidades brasileiras observam-se historicamente o negligenciamento histórico da arborização urbana dentro do planejamento e elaboração dos planos diretores das cidades, onde a mesma é apresentada de forma meramente ornamental e sem função ambiental relevante, onde o poder público por este fato tem sido paulatinamente cobrado pelas organizações civis, e tem se visto a reconsiderar na sua conceituação da importância da arborização dentro sistema urbano.

A legislação é importante para estabelecer normas, sem as quais 0 as administrações não têm como administrar os bens e os serviços sob sua responsabilidade. A legislação sobre a arborização urbana é uma preocupação antiga, embora existam muitos municípios sem uma legislação adequada ou mesmo sem nenhuma (PAIVA e GONCALVES, 2002).

Priorizar a situação de árvores e de espaços verdes na agenda dos líderes municipais e nos orçamentos públicos depende de esclarecer que o capital natural, se devidamente gerenciado, fornece retornos econômicos palpáveis para toda comunidade. Esta visão contrasta com a atitude predominante em muitas prefeituras de que a manutenção das árvores e áreas verdes só dá despesa e é pouco prioritária quando comparada com outras necessidades municipais que se presume, estão mais relacionadas com a saúde humana, a segurança e o bem-estar.

O reposicionamento do status político das florestas urbanas precisa ser seguido por ações apoiativas e planejamento a longo prazo, a coordenação profissional interdisciplinar e a participação da comunidade local, gerando assim uma sistemática das estruturas verdes urbanas,capaz de criar e desenvolver florestas em todas as regiões da cidade e sua periferia (WOLF, 2005).

Essas características marcam o direito difuso e trans-individual das áreas verdes estabelecidas pelo Código de Defesa do Consumidor (CDC) - Lei № 8.078, de 11 de setembro de 1990: Art. 81. A defesa dos interesses e direitos dos consumidores e das vítimas poderá ser exercida em juízo individualmente ou a título coletivo (Parágrafo único). 
"A defesa coletiva será exercida quando se tratar de: I - interesses ou direitos difusos, assim entendidos, para efeitos deste Código, os trans-individuais, de natureza indivisível, de que sejam titulares pessoas indeterminadas e ligadas por circunstâncias de fato. Ou seja, a existência de áreas verdes, na zona urbana, é um direito de todos, e é assegurado pelo Artigo 225 da Constituição Federal, onde está determinado que "Todos tem direito ao meio ambiente ecologicamente equilibrado, bem de uso comum do povo e essencial à sadia qualidade de vida..."

Portanto, a visão racional da escala de uma cidade não deve inibir seus administradores para os aspectos lúdicos e psicológicos que a paisagem urbana exerce sobre seus moradores. Na verdade, esses valores são imprescindíveis para que uma cidade possa se humanizar, pois conduzir o crescimento pelos caminhos que fizeram a história da cidade, preservar e valorizar as referências que nortearam gerações inteiras, são requisitos tão fundamentais a uma cidade, quanto provê-la em suas necessidades básicas, pois a cidade deixará de ser o mero espaço de sobrevivência, para se tornar o cenário da plenitude das relações humanas (Lerner, 1993).

A Lei $N^{0}$ 10.257, de 10 de Julho de 2001, O Estatuto das Cidades, regulamenta os artigos 182 e 183 da Constituição Federal e estabelece no artigo $1^{\circ}$, Parágrafo único as "normas de ordem pública e interesse social que regulam o uso da propriedade urbana em prol do bem coletivo, da segurança e do bem-estar dos cidadãos, bem como do equilíbrio ambiental". A política urbana, tratada no Artigo $2^{\circ}$ deste estatuto, estabelece que esta lei tem o objetivo de ordenar o pleno desenvolvimento das funções sociais da cidade e da propriedade urbana, mediante as seguintes diretrizes gerais:

I - garantia do direito a cidades sustentáveis, entendido como o direito à terra urbana, à moradia, ao saneamento ambiental, à infra-estrutura urbana, ao transporte e aos serviços públicos, ao trabalho e ao lazer, para as presentes e futuras gerações; (...)

VIII - adoção de padrões de produção e consumo de bens e serviços e de expansão urbana compatíveis com os limites da sustentabilidade ambiental, social e econômica do Município e do território sob sua área de influência;

XII - proteção, preservação e recuperação do meio ambiente natural e construído, do patrimônio cultural, histórico, artístico, paisagístico e arqueológico.

Os instrumentos utilizados para a aplicação desta Lei estão destacados no artigo $4^{\circ}$ : (...): III - planejamento municipal, em especial: a) plano diretor; b) disciplina do parcelamento, do uso e da ocupação do solo; c) zoneamento ambiental; VI - estudo prévio de impacto ambiental (EIA) e estudo prévio de impacto de vizinhança (EIV).

Dos instrumentos previstos no Estatuto, vale ressaltar a inclusão do zoneamento ambiental como instrumento de planejamento municipal. Segundo Carvalho e Braga (2001) "a possibilidade de um zoneamento urbano com fins explicitamente ambientais (embora o 
zoneamento urbano tradicional também tenha um forte componente ambiental) consiste num avanço, na medida em que pressupõe o estabelecimento de zonas especiais visando a preservação, melhoria e recuperação ambiental, o que inclui as áreas de proteção ambiental e as áreas verdes urbanas".

O interesse em reforçar o aspecto ambiental e assegurar a aquisição de áreas para a realização de projetos de interesse público, inclusive a implantação de áreas de proteção ambiental e áreas verdes está destacado no artigo 26 quando trata do direito de preempção será exercido sempre que o Poder Público necessitar de áreas para: VI - criação de espaços públicos de lazer e áreas verdes; VII - criação de unidades de conservação ou proteção de outras áreas de interesse ambiental; VIII - proteção de áreas de interesse histórico, cultural ou paisagístico;

A Lei 6.766, de 19 de dezembro de 1979 trata do Parcelamento do Solo Urbano, ou seja, da regulamentação técnica e jurídica do parcelamento do solo, procurando promover a organização territorial dos municípios. Através deste instrumento, o município pode exigir uma distribuição adequada dos lotes, equipamentos, vias públicas, áreas para recreação e outros usos comunitários. Segundo Barreiros e Abiko (1998) a Lei Federal 6.766/79, "veio apresentar um caráter inovador, demonstrando preocupação com a ordenação do espaço urbano, determinando indicadores mínimos de áreas públicas, de áreas e testadas de lotes e de faixas não edificáveis, estabelecendo também as condições de salubridade para a implantação de novos loteamentos".

A importância do parcelamento do solo como instrumento do Poder Público para melhor orientar a ocupação territorial e fornecer condições urbanas mínimas à população, é reforçado por Ambrosis apud Barreiros e Abiko (1998) que também considera que "uma lei que controle esse processo poderá orientar a expansão da cidade, determinando as áreas onde é permitido lotear para fins urbanos e, ao mesmo tempo, orientando quanto à preservação das áreas para produção agrícola, das áreas necessárias à proteção do meio ambiente e de áreas de proteção ao patrimônio cultural e histórico".

Com base nestes aspectos o presente estudo tem por objetivo realizar uma análise das legislações municipais, de alguns municípios, do Estado do Rio Grande do Sul referentes à arborização urbana.

\section{MATERIAL E MÉTODOS}

Para o presente estudo foram analisadas as legislações dos seguintes municípios do estado do Rio Grande do Sul. 


\section{Descrição das Cidades Estudadas}

\section{São Borja}

O município de São Borja está localizado no Oeste do Rio Grande do Sul, com uma população de 64.820 habitantes (IBGE, 2002), distribuídos em uma área de $3.371,051$ km² e densidade populacional de 19,22 hab/Km². A População distribui-se $88,74 \%$ na área urbana e 11,71\% na área rural (Prefeitura Municipal de São Borja, 2006).

\section{Santa Cruz do Sul}

O município de Santa Cruz do Sul, localiza-se na Encosta Inferior do Nordeste do Estado do Rio Grande do Sul, à 155 km de Porto Alegre. Suas coordenadas geográficas são 2943'59" Sul e 52²4'52" Oeste. A população do município é de 107.501 habitantes, onde a população urbana é de 93.650. Com um PIB de US\$1.356.221.815,83 bilhões e uma renda per capita de U\$\$12.834,02 (Prefeitura Municipal de Santa Cruz do Sul, 2006).

\section{São Paulo das Missões}

São Paulo das Missões foi fundado no ano de 1912, a criação do município efetivouse em dezembro de 1965, emancipando-se de Cerro Largo no dia 06 de Maio de 1966 (Famurs, 2006). Localiza-se à 28 01'17" Sul e 54'56'10" Oeste, estando a uma altitude de 157 metros. Sua população estimada em 2004 era de 6.502 habitantes. Possui uma área de 238,64 km² (Prefeitura Municipal de São Paulo das Missões, 2006).

\section{Quinze de Novembro}

Quinze de Novembro localiza-se a $28^{\circ} 44^{\prime} 54^{\prime \prime}$ Sul e $53^{\circ} 05^{\prime} 37^{\prime \prime}$ Oeste, estando a uma altitude de 355 metros. Sua população estimada em 2004 era de 3660 habitantes. Possui uma área de 228,38 km² (Prefeitura Municipal de Quinze de Novembro, 2006).

\section{Santo Ângelo}

O município está localizado na Região Noroeste do Rio Grande do Sul, sendo conhecido como Capital das Missões, à $286 \mathrm{~m}$ acima do nível do mar. Sua vegetação natural era distribuída em $80 \%$ de campos naturais $20 \%$ com florestas nativas. A população do município é de 76.236 habitantes (Prefeitura Municipal de Santo Ângelo, 2006).

\section{Caxias do Sul}

Caxias do Sul localiza-se na encosta superior do Nordeste do Rio Grande do Sul, parte na extremidade leste da microrregião vitivinícola e parte no planalto dos Campos de 
Cima da Serra. Em junho de 1890 foi criado o município, a população atual do município de Caxias do Sul é de 360.223 habitantes (Prefeitura Municipal de Caxias do Sul, 2006).

\section{Giruá}

Em 1927 a vila criada por imigrantes tornou-se distrito de Santo Ângelo com o nome de Passo das Pedras. Com a inauguração da estrada de ferro em 1928, a denominação de Passo das Pedras foi substituída por Giruá, qual emancipou-se em 28 de janeiro de 1955 (Prefeitura Municipal de Giruá, 2006). A população do município está estimada em 17.869 habitantes, distribuída numa área de $856 \mathrm{~km}^{2}$, estando localizado na regiao das missoes (IBGE, 2007).

\section{Pelotas}

Localizada na Encosta do Sudeste, ás margens do Canal São Gonçalo, nas coordenadas $31^{\circ}$ 46'19" Sul 52²0'33" Oeste. A primeira referência histórica do surgimento do município data de junho de 1758. A população do município é de 323.034 habitantes (Prefeitura Municipal de Pelotas, 2006), distribuídos em 1.609 km².

\section{Nonoai}

Nonoai pertenceu a Passo Fundo, a Palmeira das Missões, a Sarandi e, finalmente, no ano de 1959, através da Lei $n^{\circ} 3695$ de 30 de janeiro de 1959, foi criado o município de Nonoai. A instalação do novo município deu-se em 31 de maio de 1959, a população atual do município é de 12.962 habitantes, em uma área de 469 km² (IBGE, 2007).

\section{Uruguaiana}

Situada na microrregião Campanha Ocidental, limita-se ao norte com o município de Itaqui, ao sul com a República Oriental do Uruguai, ao leste com Alegrete e Quaraí e a oeste com a República Argentina. Sua área é de $5.452 \mathrm{Km}^{2}$ com uma população de 136.364 habitantes. A principal atividade econômica é agropecuária, com lavouras de arroz e gado de corte e reprodução. Atualmente conta com 136.364 habitantes, em uma área territorial de $5.716 \mathrm{~km}^{2}$ (Prefeitura Municipal de Uruguaiana, 2006).

\section{Metodologia Específica}

O presente estudo partiu da premissa da pesquisa de legislações municipais referentes à arborização urbana de algumas cidades gaúchas e seu confrontamento referente aos aspectos jurídico-legais em função do Código Florestal Federal (Lei $\mathrm{n}^{0}$ 4.771/65) e Estadual (Lei no 9.519/92), Lei de Crimes Ambientais (Lei n 9.605/98), Política 
Nacional do Meio Ambiente (Lei n 6.938/81), Código do Consumidor (Lei № 8.078/1990) e Estatuto das Cidades (Lei No 10.257/2001). Além dos aspectos jurídicos observaram-se aspectos técnicos recomendados nas legislações municipais quanto à indicação de espécies, implantação, manutenção, parâmetros de avaliação para o tombamento como patrimônio público, entre outros aspectos.

Com base neste contexto, para o trabalho foram analisadas as legislações municipais de Santa Cruz do Sul (Lei no 3.978/03), Caxias do Sul (Decreto no 9.361/98), São Borja (Lei Complementar n²4/01), Pelotas (Lei n 4.428/99), Giruá (Lei n²313/01), Nonoaí (Lei $n^{\circ}$ 2.205/03), Santo Ângelo (Lei $n^{\circ}$ 2.916/05), Quinze de Novembro (Lei no 540/98), São Paulo das Missões (Lei no 1029/03) e Uruguaiana (Lei n³.082/01).

\section{RESULTADOS E DISCUSSÃO}

O resultado da análise da legislação dos municípios são apresentadas no Quadro 1, das 10 Legislações municipais analisadas, 60\% apresentavam leis próprias para a arborização urbana. As demais Legislações apresentam a temática inserida na sua política de meio ambiente em poucos artigos e parágrafos, o que demonstra a pequena valorização da temática na construção de centros urbanos sustentáveis.

Sirvinskas (2003) comenta que não há dúvidas de que a arborização urbana é um dos instrumentos eficazes para minimizar os impactos negativos nos centros urbanos. Aliado, é claro, com outros instrumentos previstos nas Constituição Federal, Estadual, Leis Orgânicas dos Municípios, legislações esparsas e regulamentos, mostrando que, assim como o saneamento básico é importante para a saúde da população, a arborização urbana também é para a qualidade de vida do homem.

Outro aspecto analisado foi em relação ao direito de acesso a informação, garantido pela Política Nacional do Meio Ambiente (Lei 6.938/81 art $9^{\circ}$ inciso XI) sobre a arborização urbana nos municípios. Constatou-se que apenas três apresentavam artigos referentes ao assunto, o que fere, além desta, outras Legislações Federais, como a Lei no 10.650/03, que dispõe sobre o acesso público aos dados e informações existentes nos órgãos e entidades integrantes do SISNAMA (Sistema Nacional de Meio Ambiente), estes ficam obrigados a permitir o acesso público aos documentos, expedientes e processos administrativos que tratem de matéria ambiental e a fornecer todas as informações ambientais que estejam em sua guarda, em meio escrito, visual, sonoro ou eletrônico sobre a qualidade do meio ambiente, diversidade biológica, publicação em Diário Oficial e devendo ficar disponíveis, no respectivo órgão, nesta instância municipal, em local de fácil acesso ao público, listagens e relações contendo os dados referentes a assuntos como pedidos e licenças para a supressão de vegetação (art $2^{\circ}$, incisos I e VII e art. $4^{\circ}$ inciso II). 
Além disso, estas leis são omissas ao Capítulo IV do Estatuto das Cidades (10.257/01) sobre a gestão democrática da Cidade que coloca em seu artigo $43^{\circ}$, os instrumentos necessários para que se garanta tal condição, os quais são: I - Órgãos e colegiados de política urbana, nos níveis nacional, estadual e municipal; II - Debates, audiências e consultas públicas; III - Conferências sobre assuntos de interesse urbano, nos níveis nacional, estadual e municipal e; IV - Iniciativa popular de projeto de lei e de planos, programas e projetos de desenvolvimento urbano.

$\mathrm{Na}$ disponibilização de informações aos habitantes dos centros urbanos analisados dá-se destaque em especial para Caxias do Sul e Quinze de Novembro. Em Caxias do Sul, o envolvimento da população esta previsto na forma de conscientização e envolvimento da população para a promoção da Arborização Urbana através de programas de Educação Ambiental Popular. 
QUADRO 1: Aspectos diferenciados avaliados nas legislações municipais.

\begin{tabular}{|c|c|c|c|c|c|c|c|c|c|c|c|c|}
\hline Município & \multicolumn{2}{|c|}{ Objetivo } & \multicolumn{2}{|c|}{$\begin{array}{c}\text { Código } \\
\text { Regulador }\end{array}$} & \multicolumn{2}{|c|}{$\begin{array}{l}\text { Direito de acesso } \\
\text { à informação }\end{array}$} & Manutenção & \multicolumn{4}{|c|}{ Poda ou Supressão } & Princípios Tóxicos \\
\hline \multirow{3}{*}{$\begin{array}{l}\text { São Borja } \\
\text { Lei } 24 / 01\end{array}$} & \multirow{3}{*}{\multicolumn{2}{|c|}{$\begin{array}{llr}\text { Dispõe } & \text { sobre } & \text { a } \\
\text { política } & \text { ambiental } \\
\text { de } & \text { proteção, } \\
\text { controle, } & & \\
\text { conservação } & \text { e } \\
\text { recuperação } & \text { do } \\
\text { meio ambiente } & \text { e } \\
\text { regula } & \text { o } \\
\text { licenciamento } & \\
\text { municipal. } & \end{array}$}} & \multirow{3}{*}{\multicolumn{2}{|c|}{$\begin{array}{l}\text { Política } \\
\text { Nacional do } \\
\text { Meio Ambiente } \\
\text { (Lei 6.938/81) }\end{array}$}} & \multirow{3}{*}{\multicolumn{2}{|c|}{$\begin{array}{l}\text { "O inventário da } \\
\text { arborização deverá } \\
\text { ser realizado a } \\
\text { cada } 3 \text { anos, } \quad \cdots \\
\text { dando-se } \\
\text { publicidade." (art. } \\
\text { 84, parág. único) }\end{array}$}} & \multirow{3}{*}{$\begin{array}{l}\text { De } \\
\text { responsabilidade } \\
\text { do órgão público } \\
\text { salvo em áreas } \\
\text { particulares. }\end{array}$} & \multirow{2}{*}{\multicolumn{4}{|c|}{$\begin{array}{l}\text { "Quando o corte for indispensável à realização da obra, } \\
\text { a critério da Prefeitura Municipal, adotando-se medida } \\
\text { compensatória de } 3 \text { a } 20 \text { para cada suprimida" (art. } 78, \\
\text { inciso I). } \\
\text { Fica proibido o uso de facões,... para corte de árvores } \\
\text { localizadas nas vias, praças e logradouros públicos, ... } \\
\text { nas situadas em áreas privadas e nas áreas... de } \\
\text { relevante interesse ambiental" (art. } 83, \S 1^{\circ} \text { ) }\end{array}$}} & \multirow{3}{*}{$\begin{array}{l}\text { "O corte ou poda será } \\
\text { permitido em via pública } \\
\text { quando se tratar de } \\
\text { espécies invasoras ou } \\
\text { portadora de } \\
\text { substâncias tóxicas que } \\
\text { possam colocar em } \\
\text { risco a saúde humana e } \\
\text { animal" (art. 78, inciso } \\
\text { V). }\end{array}$} \\
\hline & & & & & & & & & & & & \\
\hline & & & & & & & & \multicolumn{4}{|c|}{$\begin{array}{l}\text { Quanto à época dar-se-á preferência para as podas } \\
\text { nas épocas de repouso vegetativo das árvores (art. 83, } \\
\S 2^{\circ} \text { ). }\end{array}$} & \\
\hline Município & Objetivo & \multicolumn{2}{|c|}{$\begin{array}{c}\text { Código } \\
\text { Regulador }\end{array}$} & $\begin{array}{l}\text { Direito } \\
\text { à inf }\end{array}$ & $\begin{array}{l}\text { acesso } \\
\text { lação }\end{array}$ & \multicolumn{2}{|r|}{ Manutenção } & \multicolumn{2}{|c|}{ Poda ou Supressão } & \multicolumn{3}{|c|}{ Princípios Tóxicos } \\
\hline \multirow{2}{*}{$\begin{array}{l}\text { Santa } \\
\text { Cruz do } \\
\text { Sul } \\
3.978 / 03\end{array}$} & \multirow{2}{*}{$\begin{array}{l}\text { Estabelece } \\
\text { normas de } \\
\text { manejo, } \\
\text { proteção e } \\
\text { conservação } \\
\text { da } \\
\text { arborização } \\
\text { no } \\
\text { município. }\end{array}$} & \multirow{2}{*}{\multicolumn{2}{|c|}{$\begin{array}{l}\text { Lei Orgânica } \\
\text { do município } \\
\text { e Código } \\
\text { Florestal } \\
\text { Estadual }\end{array}$}} & \multirow{2}{*}{\multicolumn{2}{|c|}{ Ischou }} & \multicolumn{2}{|c|}{$\begin{array}{l}\text { “.. o inventário será } \\
\text { realizado a cada } 10 \text { anos" } \\
\text { (art. 8). }\end{array}$} & \multicolumn{2}{|c|}{$\begin{array}{l}\text { "a reposição das árvores } \\
\text { suprimidas,... exige o plantio } \\
\text { de } 15 \text { mudas para cada árvore } \\
\left.\text { nativa suprimida"(art. } 10, \S 3^{\circ}\right) \text {. }\end{array}$} & \multicolumn{3}{|c|}{$\begin{array}{l}\text { A poda de ramos e galhos será autorizada para } \\
\text { fins de controle de reações alérgicas em } \\
\text { cidadãos, provocadas por aroeiras do gênero } \\
\text { Schinus e pela espécie Ligustro (Ligustrum } \\
\text { japonicum) de forma drástica..."(art. 11, inciso } \\
\text { VII)". }\end{array}$} \\
\hline & & & & & & $\begin{array}{l}\text { "O pla } \\
\text { nos p } \\
\text { poderá } \\
\text { populaç } \\
\text { acordo } \\
\text { espécie } \\
\text { municíp }\end{array}$ & $\begin{array}{l}\text { ntio e replantio... } \\
\text { asseios públicos } \\
\text { ser realizado pela } \\
\text { ão, desde que de } \\
\text { com as normas... e } \\
\text { s definidas pelo } \\
\text { io" (art. 9). }\end{array}$ & \multicolumn{2}{|c|}{$\begin{array}{l}\text { A espécie exótica Tipuana } \\
\text { deverá ser gradualmente } \\
\text { substituída, quando localizada } \\
\text { sob fiação aérea e em } \\
\text { calçadas < } 3 m \text {, mesmo que } \\
\text { não exista fiação no local."(art. } \\
15, \S 2^{\circ} \text { ). }\end{array}$} & \multicolumn{3}{|c|}{$\begin{array}{l}\text { O corte raso em áreas pertencentes ao } \\
\text { município poderá ser realizada no caso da } \\
\text { espécie exótica Ligustro (Ligustrum japonicum) } \\
\text { que deverá ser substituída por outras espécies, } \\
\text { em função das reações alérgicas que seu pólen } \\
\text { causa em parte da população."(art. } 15 \S^{\circ} \text { ). }\end{array}$} \\
\hline Município & \multicolumn{2}{|c|}{ Objetivo } & \multicolumn{2}{|c|}{$\begin{array}{l}\text { Código } \\
\text { Regulador }\end{array}$} & \multicolumn{2}{|c|}{$\begin{array}{l}\text { Direito de acesso } \\
\text { à informação }\end{array}$} & \multicolumn{2}{|c|}{ Manutenção } & \multicolumn{2}{|c|}{$\begin{array}{l}\text { Poda ou } \\
\text { Supressão }\end{array}$} & \multicolumn{2}{|c|}{ Princípios Tóxicos } \\
\hline $\begin{array}{l}\text { São Paulo } \\
\text { das } \\
\text { Missões }\end{array}$ & \multirow{2}{*}{\multicolumn{2}{|c|}{$\begin{array}{l}\text { Estabelece normas } \\
\text { de proteção e } \\
\text { promoção da } \\
\text { arborização urbana } \\
\text { do município de São } \\
\text { Paulo das Missões }\end{array}$}} & \multirow{2}{*}{\multicolumn{2}{|c|}{$\begin{array}{l}\text { Lei Orgânica } \\
\text { do município }\end{array}$}} & \multirow{2}{*}{\multicolumn{2}{|c|}{-}} & $\begin{array}{l}\text { "Deverá ser prioriz } \\
\text { essências nativas } \\
\text { compatíveis } \\
\text { estabelecidas } \\
\text { regulamento..." (art }\end{array}$ & $\begin{array}{lr}\text { ado o } & \text { plantio de } \\
\text { ou } & \text { exóticas, } \\
\text { as } & \text { normas } \\
\text { elo } & \text { presente } \\
6) & \end{array}$ & \multirow{2}{*}{\multicolumn{2}{|c|}{$\begin{array}{l}\text { É proibido o corte } \\
\text { ou remoção de } \\
\text { árvores para a } \\
\text { instalação de } \\
\text { luminosos, } \\
\text { letreiros, toldos ou } \\
\text { similares (art. 11). }\end{array}$}} & \multirow{2}{*}{\multicolumn{2}{|c|}{$\begin{array}{l}\text { A poda de árvores da espécie Ligustrum } \\
\text { sp. deverá ter condução da copa } \\
\text { diferenciada das demais, com a finalidade } \\
\text { de formação de copada, e inibição do } \\
\text { florescimento, devendo apenas estender- } \\
\text { se também, as árvores da espécie que se } \\
\text { encontram sob rede elétrica, até sua } \\
\text { substituição gradativa (art. } 21, \S 1^{\circ} \text { ) }\end{array}$}} \\
\hline $\begin{array}{c}\text { Lei } \\
1.029 / 03\end{array}$ & & & & & & & $\begin{array}{l}\text { "As mudas das á } \\
\text { plantadas dever } \\
\text { mínima de } 1,2 \mathrm{~m} . .\end{array}$ & $\begin{array}{l}\text { rvores a } \text { serem } \\
\text { à } \quad \text { ter } \\
\text { "(art. } 7) \text { altura }\end{array}$ & & & & \\
\hline
\end{tabular}




\begin{tabular}{|c|c|c|c|c|c|c|c|c|c|c|c|}
\hline Município & Objetivo & $\begin{array}{l}\text { Código } \\
\text { Regulador }\end{array}$ & & $\begin{array}{l}\text { Direito de acesso à } \\
\text { informação }\end{array}$ & \multicolumn{3}{|c|}{ Manutenção } & \multicolumn{2}{|r|}{$\begin{array}{l}\text { Poda ou } \\
\text { Supressão }\end{array}$} & & $\begin{array}{l}\text { Princípios } \\
\text { Tóxicos }\end{array}$ \\
\hline \multirow{3}{*}{$\begin{array}{l}\text { Quinze de } \\
\text { Novembro } \\
\text { Lei 540/98 }\end{array}$} & \multirow{3}{*}{$\begin{array}{l}\text { Disciplina a } \\
\text { arborização } \\
\text { urbana no } \\
\text { Município de } \\
\text { Quinze de } \\
\text { Novembro e } \\
\text { dá outras } \\
\text { providências. }\end{array}$} & \multirow{3}{*}{$\begin{array}{l}\text { Lei } \\
\text { Orgânica } \\
\text { do } \\
\text { Município } \\
\text { e Código } \\
\text { Florestal } \\
\text { Federal } \\
(4.771 / 65)\end{array}$} & \multirow{3}{*}{\multicolumn{2}{|c|}{$\begin{array}{l}\text { Fica criada pela força } \\
\text { desta lei e } \\
\text { oficializada pela força } \\
\text { desta lei a Comissão } \\
\text { de Arborização } \\
\text { Urbana..., compete } \\
\text { estudar, analisar e } \\
\text { opinar sobre os } \\
\text { assuntos pertinentes } \\
\text { à arborização urbana } \\
\left(\text { arts. } 4^{\circ} \text { e } 5^{\circ}\right) \text {. }\end{array}$}} & \multicolumn{3}{|c|}{$\begin{array}{l}\text { Fica proibido o plantio de árvores, a poda ou supressão total de } \\
\text { espécies, tanto por particulares quanto pela Prefeitura Municipal, nas } \\
\text { vias e logradouros públicos, quando não estiverem de acordo com as } \\
\text { normas da Comissão de arborização e pelo Plano de Arborização } \\
\text { Urbana }\left(\operatorname{art} 7^{\circ}\right) \text {. }\end{array}$} & \multirow{3}{*}{\multicolumn{2}{|c|}{$\begin{array}{lr}\text { Quando } & \text { a } \\
\text { comissão } & \text { de } \\
\text { Arborização } & \\
\text { Urbana ou o órgão } \\
\text { municipal de meio } \\
\text { ambiente } & \text { julgar } \\
\text { necessário, } & \\
\text { embasados } & \text { no } \\
\text { plano } & \text { de } \\
\text { arborização urbana } \\
\text { (art. 15 Inciso VII). }\end{array}$}} & \\
\hline & & & & & \multicolumn{3}{|c|}{$\begin{array}{l}\text { A Prefeitura fica responsável pelo treinamento de uma equipe de } \\
\left.\text { plantio e manejo que realizará todas as atividades (art } 9^{\circ}\right)\end{array}$} & & & & \\
\hline & & & & & \multicolumn{3}{|c|}{$\begin{array}{l}\text { A Prefeitura deverá contar com os serviços de um técnico } \\
\text { especializado na área, para a elaboração do inventário da arborização } \\
\text { urbana atual localizada nas vias e praças públicas e para a elaboração } \\
\text { do Plano de Arborização Urbana, este com a finalidade de orientar } \\
\text { sobre as técnicas de plantio, manejo e espécies adequadas (art 14). }\end{array}$} & & & & \\
\hline Município & Objetivo & \multicolumn{2}{|c|}{$\begin{array}{l}\text { Código } \\
\text { Regulador }\end{array}$} & \begin{tabular}{|l|} 
Direito de acesso \\
à informação
\end{tabular} & \multicolumn{5}{|c|}{\begin{tabular}{|c|c|} 
Manutenção & Poda ou Supressão
\end{tabular}} & \multicolumn{2}{|r|}{$\begin{array}{l}\text { Princípios } \\
\text { Tóxicos }\end{array}$} \\
\hline \multirow{3}{*}{$\begin{array}{l}\text { Santo } \\
\text { Ângelo }\end{array}$} & \multirow{3}{*}{$\begin{array}{l}\text { Estabelece } \\
\text { normas de } \\
\text { proteção e } \\
\text { promoção da } \\
\text { arborização } \\
\text { do município } \\
\text { de Santo } \\
\text { Ângelo }\end{array}$} & \multirow{3}{*}{\multicolumn{2}{|c|}{$\begin{array}{l}\text { Constituição } \\
\text { Federal, } \\
\text { Código } \\
\text { Florestal } \\
\text { Estadual e } \\
\text { Lei Orgânica } \\
\text { do Município. }\end{array}$}} & & \multicolumn{2}{|c|}{ 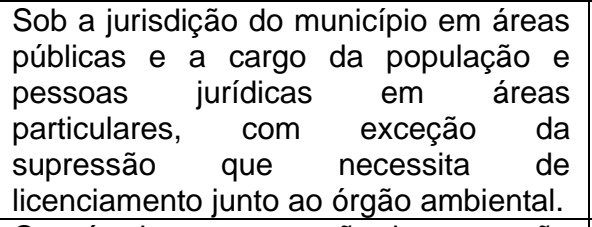 } & \multicolumn{3}{|c|}{$\begin{array}{l}\text { É vedada a poda drástica ou excessiva da } \\
\text { arborização pública ou privada (art 27). }\end{array}$} & \multirow{3}{*}{\multicolumn{2}{|c|}{$\begin{array}{l}\text { É permitida a } \\
\text { poda } \\
\text { diferenciada } \\
\text { para os } \\
\text { ligustros, sob a } \\
\text { orientação do } \\
\text { Órgão } \\
\text { Ambiental do do } \\
\text { município, } \\
\text { efetuando } \\
\text { retirada dos } \\
\text { galhos em } \\
\text { floração, } \\
\text { visando } \\
\text { reduzir,..., } \\
\text { impacto sobre } \\
\text { os alérgicos } \\
\text { (art 28). }\end{array}$}} \\
\hline & & & & & \multicolumn{2}{|c|}{$\begin{array}{l}\text { O estímulo a preservação da vegetação } \\
\text { nas áreas particulares integrantes do } \\
\text { Sistema de Áreas Verdes (SAV) poderá } \\
\text { ser dado por meio de incentivos fiscais } \\
\left(\text { art } 10^{\circ}\right) \text {. }\end{array}$} & \multicolumn{3}{|c|}{$\begin{array}{l}\text { A remoção de árvores em vias e logradouros } \\
\text { públicos será permitida quando o requerente já } \\
\text { tiver efetuado a reposição com a espécie } \\
\text { recomendada e árvore plantada estiver } \\
\text { plenamente adaptada ao local e biologicamente } \\
\text { estabelecida,..., com altura mínima de } 3,0 \text { m... (art. } \\
30 \S 7^{\circ} \text { ). }\end{array}$} & & \\
\hline & & & & & \multicolumn{2}{|c|}{$\begin{array}{l}\text { Não é permitido utilizar a arborização } \\
\text { existente como suporte para quaisquer } \\
\text { materiais (placas, cartazes, faixas, } \\
\text { sacos de lixo, arames, pregos, etc, que } \\
\text { venham a danificar as árvores), ficando } \\
\text { expressamente proibido pintar ou pichar } \\
\text { as árvores (art 19). }\end{array}$} & \multicolumn{3}{|c|}{$\begin{array}{l}\text { Todo o proprietário de terreno urbano, } \\
\text { independente de ter edificação ou não, que não } \\
\text { possuir árvores em frente ao referido terreno, } \\
\text { deverá providenciar o plantio de no mínimo, } 1 \\
\text { árvore em frente ao terreno de sua propriedade, de } \\
\text { acordo com as orientações e especificações do } \\
\text { Órgão Público Ambiental do município (art 41). } \\
\end{array}$} & & \\
\hline Município & Objetivo & $\begin{array}{l}\text { :ódigo } \\
\text { gulador }\end{array}$ & \multicolumn{3}{|c|}{$\begin{array}{l}\text { Direito de acesso de } \\
\text { informação }\end{array}$} & \multicolumn{3}{|c|}{ Manutenção } & \multicolumn{2}{|l|}{$\begin{array}{l}\text { Poda ou } \\
\text { Supressão }\end{array}$} & $\begin{array}{l}\text { Princípios } \\
\text { Tóxicos }\end{array}$ \\
\hline \multirow[b]{2}{*}{$\begin{array}{l}\text { Caxias do } \\
\text { Sul } \\
\text { Lei } \\
9.361 / 98\end{array}$} & \multirow{2}{*}{$\begin{array}{l}\text { Estabelece } \\
\text { normas para } \\
\text { a arborização } \\
\text { urbana e } \\
\text { outras } \\
\text { providências }\end{array}$} & \multirow[b]{2}{*}{$\begin{array}{c}\text { Lei } \\
\text { Orgânica } \\
\text { do } \\
\text { município }\end{array}$} & \multirow{2}{*}{\multicolumn{3}{|c|}{$\begin{array}{l}\text { Com a intenção de envolver } \\
\text { e conscientizar a população } \\
\text { no plantio e preservação da } \\
\text { arborização serão } \\
\text { elaborados programas e } \\
\text { materiais distribuídos à } \\
\text { população (art. 10) }\end{array}$}} & $\begin{array}{l}\text { O plantio das mudas se dará, pref } \\
\text { e setembro, aproveitando o períod }\end{array}$ & $\begin{array}{l}\text { ferencialmente, entre o mês de ju } \\
\text { o de chuva (art. } 5 \text { Inciso IV) }\end{array}$ & & \multirow{2}{*}{\multicolumn{2}{|c|}{$\begin{array}{|lr|}\text { As podas em } \\
\text { vias públicas são } \\
\text { de inteira } \\
\text { responsabilidade } \\
\text { da Prefeitura } \\
\text { Municipal (art } \\
\text { 12). } \\
\end{array}$}} & \\
\hline & & & & & & $\begin{array}{l}\text { As recomendações de espaçam } \\
\text { entre árvores: diâmetro de copa; } \\
\text { verticais, como postes, etc., o } \\
\text { equipamentos (hidrante, boca-d } \\
\text { observando ainda o sistema radicı }\end{array}$ & $\begin{array}{l}\text { ento falam de valores mínimos: } \\
\text { b) entre árvores e outros elemer } \\
\text { raio de copa; d) entre árvores } \\
\text { e-lobo, etc.), o espaço de } 1, \\
\text { lar de cada espécie (art. 6). }\end{array}$ & & & & \\
\hline
\end{tabular}




\begin{tabular}{|c|c|c|c|c|c|c|c|c|c|}
\hline Município & Objetivo & $\begin{array}{c}\text { Código } \\
\text { Requlador }\end{array}$ & $\begin{array}{c}\text { Direito de acesso } \\
\text { à informacão }\end{array}$ & Manutenção & \multicolumn{2}{|c|}{ Poda ou Supressão } & \multicolumn{3}{|c|}{ Princípios Tóxicos } \\
\hline \multirow{2}{*}{$\begin{array}{l}\text { Giruá } \\
\text { Lei } \\
2.313 / 01\end{array}$} & \multirow{2}{*}{$\begin{array}{l}\text { Estabelec } \\
\text { e normas } \\
\text { de } \\
\text { proteção e } \\
\text { promoção } \\
\text { da } \\
\text { arborizaçã } \\
\text { o urbana } \\
\text { no } \\
\text { município } \\
\text { de Giruá. }\end{array}$} & \multirow{2}{*}{$\begin{array}{l}\text { Lei Orgânica } \\
\text { do Município }\end{array}$} & \multirow[t]{2}{*}{ 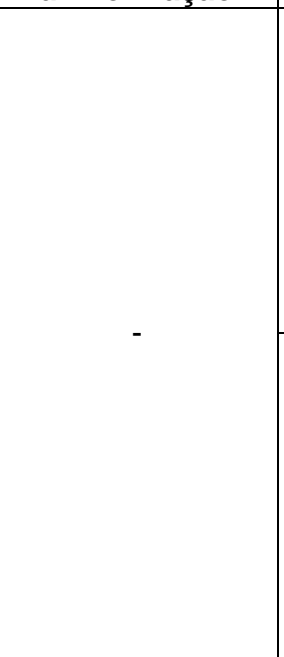 } & $\begin{array}{l}\text { Os projetos de loteamentos a serem } \\
\text { aprovados a partir da publicação da } \\
\text { presente lei deverão prever a implantação } \\
\text { da arborização urbana, com o plantio e } \\
\text { manutenção das mesmas, respeitando as } \\
\text { normas do presente regulamento e } \\
\text { evitando conflitos com equipamentos } \\
\text { urbanos (art. } 163^{\circ} \text { ) }\end{array}$ & \multicolumn{2}{|c|}{$\begin{array}{l}\text { É vedado o corte, a poda, a } \\
\text { derrubada ou a prática de } \\
\text { qualquer ação que possa } \\
\text { provocar dano, alteração do } \\
\text { desenvolvimento natural ou } \\
\text { morte de árvore em área } \\
\text { pública, salvo aquelas } \\
\text { situações previstas no presente } \\
\text { regulamento }\left(\text { art. } 8^{\circ}\right) \text {. }\end{array}$} & \multicolumn{3}{|c|}{$\begin{array}{l}\text { As árvores da espécie exótica } \\
\text { Ligustrum sp., deverão ter condução } \\
\text { da copa diferenciada das demais, } \\
\text { com a finalidade de formação de } \\
\text { copada, e inibição do florescimento }\end{array}$} \\
\hline & & & & $\begin{array}{l}\text { Em áreas privadas o plantio ou condução } \\
\text { de árvores ficará de responsabilidade do } \\
\text { proprietário. A remoção de árvores } \\
\text { nativas ou exóticas deverá ter autorização } \\
\text { da Prefeitura Municipal, que poderá } \\
\text { remeter a situação para análise do } \\
\text { Conselho municipal do Meio Ambiente, } \\
\text { quando couber (art. } 20 \text { § único). }\end{array}$ & \multicolumn{2}{|c|}{$\begin{array}{l}\text { É atribuição exclusiva da } \\
\text { Prefeitura Municipal, através do } \\
\text { Setor competente, podar, } \\
\text { cortar derrubar ou remover } \\
\text { árvores localizadas em áreas } \\
\text { públicas (art. 17). }\end{array}$} & \multicolumn{3}{|c|}{$\begin{array}{l}\text { Conforme resolução } \mathrm{n}^{\circ} 001 / 2006 \text { do } \\
\text { Conselho Municipal de Meio } \\
\text { Ambiente, devendo estender-se, } \\
\text { também as árvores da referida } \\
\text { espécie que não se encontram } \\
\text { abaixo da rede elétrica, até a } \\
\text { substituição gradativa de todos os } \\
\text { exemplares das vias públicas (art. } \\
21, \S 1^{\circ} \text { ) }\end{array}$} \\
\hline Município & Objetivo & $\begin{array}{c}\text { Código } \\
\text { Regulador }\end{array}$ & $\begin{array}{l}\text { Direito de acesso } \\
\text { à informação }\end{array}$ & \multicolumn{2}{|l|}{ Manutenção } & \multicolumn{3}{|c|}{ Poda ou Supressão } & $\begin{array}{l}\text { Princípios } \\
\text { Tóxicos }\end{array}$ \\
\hline \multirow{3}{*}{$\begin{array}{l}\text { Pelotas } \\
\text { Lei } \\
4.428 / 99\end{array}$} & \multirow{3}{*}{$\begin{array}{l}\text { Dispõe } \\
\text { sobre a flora } \\
\text { nativa e } \\
\text { exótica } \\
\text { localizada } \\
\text { no município } \\
\text { de Pelotas e } \\
\text { dá outras } \\
\text { providências }\end{array}$} & \multirow{3}{*}{$\begin{array}{l}\text { Lei } \\
\text { ambiental } \\
\text { do } \\
\text { município }\end{array}$} & \multirow{3}{*}{-} & \multirow{3}{*}{\multicolumn{2}{|c|}{$\begin{array}{l}\text { Os espécimes da flora a qual trata esta lei poderão sofrer } \\
\text { dendrocirurgia, supressão ou transplante (art } 3^{\circ} \text { ) } \\
\text { O plantio a qual trata a Lei será feito preferencialmente em } \\
\text { locais carentes de arborização, nas áreas verdes ou praças } \\
\text { não adotadas nos termos da Lei Municipal } n^{\circ} 4125 / 96 \text { e nas } \\
\left.\text { Reservas Ecológicas (art } 3^{\circ}, \S 5^{\circ}\right) \\
\text { Para aprovação de parcelamento de uso do solo sob a forma } \\
\text { de arruamento e loteamento, o interessado deverá apresentar } \\
\text { projeto de arborização de vias públicas }\left(\text { art } 7^{\circ}\right) \text {. }\end{array}$}} & \multirow{3}{*}{\multicolumn{3}{|c|}{$\begin{array}{l}\text { Em casos de supressão, o Órgão } \\
\text { ambiental municipal e, na sua } \\
\text { omissão, o COMPAM, exigirá a } \\
\text { reposição, ..., pelo plantio de } \\
\text { espécimes da flora nativa..., } \\
\text { preferencialmente ameaçados de } \\
\text { extinção, na proporção mínima de } \\
5 \text { novos para cada um suprimido... } \\
\left(\text { art. } 3^{\circ}, \S 3^{\circ}\right) \text {. }\end{array}$}} & \multirow[t]{3}{*}{ C } \\
\hline & & & & & & & & & \\
\hline & & & & & & & & & \\
\hline Município & Objetivo & $\begin{array}{c}\text { Código } \\
\text { Regulador }\end{array}$ & $\begin{array}{l}\text { Direito de acesso } \\
\text { à informação }\end{array}$ & \multicolumn{4}{|c|}{ Manutenção } & $\begin{array}{l}\text { Poda ou } \\
\text { Supressão }\end{array}$ & $\begin{array}{l}\text { Princípios } \\
\text { Tóxicos }\end{array}$ \\
\hline \multirow{3}{*}{$\begin{array}{l}\text { Nonoai } \\
\text { Lei } \\
2.205 / 03\end{array}$} & \multirow{3}{*}{$\begin{array}{l}\text { Trata da } \\
\text { política } \\
\text { Ambiental } \\
\text { de proteção, } \\
\text { controle, } \\
\text { conservação } \\
\text { e recuperação } \\
\text { do meio } \\
\text { ambiente e } \\
\text { dá outras } \\
\text { providências }\end{array}$} & \multirow{3}{*}{$\begin{array}{c}\text { Lei } \\
\text { Orgânica } \\
\text { Municipal }\end{array}$} & & \multicolumn{4}{|c|}{$\begin{array}{l}\text { O município desenvolverá programas de manutenção e expansão de } \\
\text { arborização com as seguintes metas: I) manter viveiro próprio ou convênio com } \\
\text { instituições e viveiros para a recomposição da flora nativa e a produção de } \\
\text { espécies vegetais diversas destinadas a arborização; II) promover ampla } \\
\text { arborização dos logradouros públicos da área urbana utilizando cinqüenta por } \\
\text { cento de espécies frutíferas ou nativas (art. 10, incisos I e II) }\end{array}$} & \multirow{3}{*}{$\begin{array}{l}\text { A população é } \\
\text { responsável pela } \\
\text { conservação da } \\
\text { arborização das } \\
\text { vias públicas, } \\
\text { devendo } \\
\text { denunciar cortes } \\
\text { ou podas } \\
\text { irregulares no } \\
\text { órgão ambiental } \\
\left(\text { art } 10, \delta 1^{\circ}\right) \text {. }\end{array}$} & \multirow[t]{3}{*}{ ( } \\
\hline & & & & \multicolumn{4}{|c|}{$\begin{array}{l}\text { É de competência do município o plantio de árvores em logradouros públicos, } \\
\left.\text { sendo que definirá o local e a espécie vegetal mais apropriada (art } 10, \S 1^{\circ}\right) \text {. }\end{array}$} & & \\
\hline & & & & \multicolumn{4}{|c|}{$\begin{array}{l}\text { A pessoa física ou jurídica poderá plantar espécies vegetais na via pública } \\
\text { obedecidas normas regulamentares do órgão ambiental municipal e se } \\
\text { responsabilizar pela manutenção. No caso de dano ao calçamento, deverá pedir } \\
\left.\text { autorização de corte ou poda ao órgão ambiental municipal (art } 10, \S 1^{\circ}\right)\end{array}$} & & \\
\hline
\end{tabular}




\begin{tabular}{|c|c|c|c|c|c|c|}
\hline Município & Objetivo & $\begin{array}{l}\text { Código } \\
\text { Regulador }\end{array}$ & $\begin{array}{l}\text { Direito de acesso } \\
\text { à informação }\end{array}$ & Manutenção & $\begin{array}{l}\text { Poda ou } \\
\text { Supressão }\end{array}$ & $\begin{array}{l}\text { Princípios } \\
\text { Tóxicos }\end{array}$ \\
\hline \multirow[t]{3}{*}{$\begin{array}{l}\text { Uruguaiana } \\
\text { Lei } \\
3.082 / 01\end{array}$} & \multirow{3}{*}{$\begin{array}{l}\text { Dispõe } \\
\text { sobre a } \\
\text { política } \\
\text { Municipal de } \\
\text { Meio } \\
\text { Ambiente e } \\
\text { dá outras } \\
\text { providência. }\end{array}$} & \multirow[t]{3}{*}{$\begin{array}{l}\text { Lei Orgânica } \\
\text { do Município }\end{array}$} & \multirow[t]{3}{*}{-} & $\begin{array}{l}\text { O município desenvolverá programas de manutenção e expansão de } \\
\text { arborização com as seguintes metas: I) manter viveiro próprio ou convênio com } \\
\text { instituições e viveiros para a recomposição da flora nativa e a produção de } \\
\text { espécies vegetais diversas destinadas a arborização; II) promover ampla } \\
\text { arborização dos logradouros públicos da área urbana utilizando cinqüenta por } \\
\text { cento de espécies frutíferas ou nativas (art. 15, incisos I e II) }\end{array}$ & \multirow{3}{*}{$\begin{array}{l}\text { A população é } \\
\text { responsável pela } \\
\text { conservação da } \\
\text { arborização das } \\
\text { vias públicas, } \\
\text { devendo } \\
\text { denunciar cortes } \\
\text { ou podas } \\
\text { irregulares no } \\
\text { órgão ambiental } \\
\left(\text { art 15, } \S 3^{\circ}\right) \text {. }\end{array}$} & \multirow[t]{3}{*}{-} \\
\hline & & & & $\begin{array}{l}\text { É de competência do município o plantio de árvores em logradouros públicos, } \\
\text { sendo que definirá o local e a espécie vegetal mais apropriada (art } 15, \S 1^{\circ} \text { ) }\end{array}$ & & \\
\hline & & & & $\begin{array}{l}\text { A pessoa física ou jurídica poderá plantar espécies vegetais na via pública } \\
\text { obedecidas as normas regulamentares do órgão ambiental municipal e se } \\
\text { responsabilizar pela manutenção.... No caso de dano ao calçamento,..., a } \\
\text { pessoa física ou jurídica deverá pedir autorização de corte ao órgão ambiental } \\
\text { municipal }\left(\text { art } 15, \S 1^{\circ} \text { ) ou poda de árvores públicas ao órgão ambiental }\right. \\
\left.\text { municipal (art } 15, \S 2^{\circ}\right)\end{array}$ & & \\
\hline
\end{tabular}


Segundo Paiva e Gonçalves (2002), a participação comunitária no processo de arborização de um bairro ou cidade constitui-se de um ato de cidadania e, por si só, um processo de educação ambiental.

Porém, deve-se ressaltar que a forma de inserção desta comunidade na ação não deve se resumir apenas no auxílio ao plantio de mudas ou meramente como público de palestras extremamente técnicas de indicação de espécies adequadas para plantio em ruas, mas levar a população a entender a ação da arborização urbana, como um processo de projeto comunitário, aonde vai se criando e reconstruindo laços estreitos de comprometimento e de responsabilidade entre as pessoas e organismos da comunidade (escolas, grupos de idosos, lideranças religiosas, grupo de jovens) e o seu meio local, igualmente construindo um meio de vida onde reinem relações harmoniosas entre as pessoas e o meio, procurando melhorar a qualidade das condições ambientais e das relações humanas (LISOVSKI e ZAKREZEVSKI, 2003).

Tal inserção e conscientização resultam na redução de um dos maiores problemas enfrentados pelos gestores municipais dos centros urbanos brasileiros na implantação e manutenção de planos de arborização urbana, que é o vandalismo. Conforme Malavasi e Malavasi (2001), é necessária a constante integração dos moradores nos projetos de arborização urbana para que se elimine este tipo de agressão, pois através da avaliação de suas percepções sobre a arborização e também sua educação e conscientização dos efeitos e necessidade da arborização em seu bairro ou município, o morador se sentirá um ator social atuante dentro do processo.

Em Quinze de Novembro insere-se a participação e acesso da população a informações referentes à arborização urbana por meio da Comissão de Arborização Urbana, que dentro do município sagra-se como órgão responsável pela análise e estudo dos assuntos referentes ao tema no município, envolvendo vários grupos, entidades da população, que por sua vez cumprem o que se encontra disposto no Estatuto das Cidades Capítulo IV, art 45, onde os organismos gestores das regiões metropolitanas e aglomerações urbanas incluirão obrigatória e significativa participação da população e de associações representativas dos vários segmentos da comunidade, de modo a garantir o controle direto de suas atividades e pleno exercício da cidadania.

Quanto ao plantio e manutenção da arborização nas vias e logradouros públicos, em todas as legislações, encontra-se como responsável para sua promoção o Município através de suas Secretarias, sendo em alguns casos repassados para a população como no caso dos municípios de Santa Cruz do Sul, Nonoai e Uruguaiana, sendo que estes plantios e manutenções obedecem a instruções técnicas do Órgão Municipal designado competente.

Nas áreas particulares, em todos municípios, houve a responsabilização para os respectivos donos (pessoas físicas e jurídicas), salvo a poda e supressão de árvores, que 
fica designada à Prefeitura. Dentro das legislações, destaca-se o Sistema de Áreas Verdes (SAV) de Santo Ângelo, que no artigo $10^{\circ}$ coloca que a preservação de vegetação nas áreas particulares de interesse ou integrantes do SAV podem receber incentivos fiscais para tal preservação, o que por sua vez estimula a população ao plantio de árvores e incremento da malha verde urbana do município garantindo inúmeros benefícios ambientais.

Outra atitude pioneira seria a de Quinze de Novembro, que instituiu a criação do Plano de Arborização Municipal, um setor de arborização urbana dentro do Órgão Municipal munido de equipes especializadas para tratar da arborização, o que tem a conferir à população serviços de qualidade, melhoria e principalmente atendimento das demandas comunitárias e a construção de um centro urbano realmente sustentável, assim seguindo o exemplo da Cidade de Porto Alegre, que em 1924, através do Ato $n^{\circ} 341$, institui a criação do Serviço de Jardins e Arborização dos Logradouros Públicos sob a jurisdição da Diretoria de Obras da época, e em 1976 criando a primeira Secretaria Municipal do Meio Ambiente confere a Porto Alegre o título da cidade mais arborizada do estado com um índice de área verde de $14,11 \mathrm{~m}^{2} / \mathrm{hab}$, acima até mesmo os padrões da Organização Mundial da Saúde (OMS) que é de $12 \mathrm{~m}^{2} / \mathrm{hab}$ (MENEGAT et al., 1998).

No município de Caxias do Sul, ressalva-se a estipulação do período recomendado para o plantio de mudas na arborização urbana, indicando o início do inverno, o que para a manutenção por parte dos moradores possibilita uma maior chance de sucesso na implantação, pelo maior índice de chuvas e temperatura mais amena, desonerando o desprendimento de mão-de-obra para a irrigação e evitando a evapotranspiração excessiva das mudas.

Porém, a legislação apresenta problemas técnicos na orientação técnica para espaçamento entre árvores para implantação, que segundo esta é de apenas o diâmetro da copa, o que poderá ocasionar uma série de problemas futuros ao longo do desenvolvimento destas árvores, como excesso de sombreamento às edificações durante o período de inverno, que faz crescerem vertiginosamente as demandas de podas, além de gerar competição por espaço entre as árvores. A distância mínima para o plantio recomendado varia de 6 a $12 \mathrm{~m}$ entre árvores (GUIMARÃES, 2004), podendo chegar até $15 \mathrm{~m}$ quando a rua for arborizada preferencialmente com espécies de médio a grande porte (SILVA e BORTOLETO, 2006).

Outras práticas técnicas equivocadas observadas nas legislações municipais seriam, por exemplo, a recomendação de dendrocirurgias nas árvores das vias públicas, indicada na legislação de Pelotas (art $3^{\circ}$ ), que consiste na retirada de estruturas "apodrecidas" das árvores pela ação de fungos e aplicação de cimento ou poliuretano no local para obstruir a ação destes organismos, que na maioria das vezes leva as árvores à morte pela intoxicação 
de seus tecidos ou debilitação e suscetibilização a ataque de pragas, devido a princípios tóxicos contidos nos materiais utilizados para o auxílio da cicatrização da dendrocirurgia.

A questão biodiversidade de espécies dentro dos centros urbanos é bastante premente para que se garanta a sustentabilidade do sistema urbano, abordada na arborização através da implantação e valorização da flora nativa, como se observa em várias legislações, mais fortemente implícita na legislação municipal de Pelotas (Lei no 4.428/99). Porém, cabe lembrar que não se deve erradicar totalmente as "espécies ditas exóticas" pois, acima de tudo, as mesmas representam à identidade cultural dos povos colonizadores de nosso estado.

Conforme Backes e Irgang (2004), algumas árvores são marcantes na cultura paisagística étnica das diferentes regiões culturais do sul do Brasil, como o Plátano para os italianos, o Cipreste para os portugueses, os Pinheiros para os alemães e asiáticos e o Cinamomo para o gaúcho, pois possuem alguma razão cultural para seu uso, seja para produzir sombra, alimento, utensílios ou simplesmente embelezar a paisagem e talvez evocar algo da terra ancestral.

A análise das leis municipais quanto a implantação de novos loteamentos e adequação dos loteamentos já implantados quanto à vegetação existente, e a obrigatoriedade da apresentação de projeto de implantação de áreas verdes e arborização das vias públicas por parte dos loteadores, representa também um grande passo para a ampliação da cobertura verde dos municípios, pois em décadas anteriores os planos de parcelamento do solo e leis ambientais dos municípios não previam tais necessidades, o que desonerava os loteadores de tais atividades, deixando o ônus da implantação para associação de moradores do loteamento novo, que na maioria dos casos não podia implanta-los por falta de recursos.

Um aspecto evidenciado em duas legislações municipais, de São Borja e Santa Cruz do Sul, merece destaque, que é a abordagem e instauração do inventário da arborização urbana, que tem por objetivo possibilitar o conhecimento do patrimônio arbóreo da área urbana do município e apontar diretrizes para os planos de arborização, o que é amparado pelo Estatuto das cidades, artigo $2^{\circ}$, que coloca que a política urbana tem por objetivo ordenar o pleno desenvolvimento das funções sociais da cidade e da propriedade mediantes as seguintes diretrizes: Inciso I - garantia do direito a cidades sustentáveis; Inciso VI - ordenamento e controle do uso do solo de forma a evitar: f) a deterioração das áreas urbanizadas; g) a poluição e a degradação ambiental; XII - proteção, preservação e recuperação do meio natural e construído, do patrimônio cultural, histórico, artístico, paisagístico e arqueológico.

A questão mais polêmica dentro das legislações municipais referente à arborização urbana é quanto à poda e supressão (corte) de árvores. Neste aspecto é que se encontram 
os maiores equívocos por parte da população, pela falta de acesso a informação ou de entendimento das legislações municipais, evidenciando-se um profundo negligenciamento por parte de muitos gestores municipais ao cumprimento da Lei $n^{\circ} 10.650 / 03$, que dispõe sobre o acesso público aos dados e informações dos órgãos do Sisnama, que trata inclusive no art. $4^{\circ}$, inciso II, que devem ficar a disposição da população, listagens e relações contendo os dados referentes a assuntos como pedidos e licenças para a supressão de vegetação, e informações sobre os procedimentos necessários para o licenciamento de podas e supressões.

Este desconhecimento pode levar diretamente à aplicação de medidas punitivas ao cidadão por alguma ação ilegal realizada, o que cria empatia e desmotivação na população a participar dos planos de arborização, aspecto que poderia ser sanado por meio da informação sobre a legislação municipal vigente e a aplicação de medidas punitivas somente em casos de reincidência no ato.

Analisando-se os artigos referentes à poda e supressão nas Legislações Municipais, chama-se a atenção para o artigo $15 \S 2^{\circ}$ da Lei 3.978/03 que dispõe sobre a arborização do município de Santa Cruz do Sul, que coloca: "a espécie exótica Tipuana deverá ser gradualmente substituída, quando localizada sob a fiação aérea e em calçadas $<3 \mathrm{~m}$ de largura, mesmo que não exista fiação local".

O presente artigo representa uma "medida paleativa" a erros de implantação de uma espécie cometidos anteriormente a formulações de Legislações de regramento do uso e parcelamento do solo e de normatização para a arborização, portanto deve-se verificar que os problemas não são advindos da espécie, mas sim pela forma como a mesma se encontra implantada, por exemplo, em calçadas estreitas, com área livre para desenvolvimento do sistema radicular totalmente concretada até a base do tronco, não permitindo o pleno desenvolvimento das raízes e por fim ocasionando danos ao calçamento.

O uso inadequado do solo destinado à área de calçamento e formação de áreas livres para arborização urbana é considerado crime ambiental, previsto na Lei no 9.605/98 Lei de Crimes Ambientais, onde na Seção IV - dos Crimes contra o ordenamento urbano e patrimônio cultural, no artigo 64, consta que "promover construção em solo não edificável, ou no seu entorno, assim considerado pelo valor paisagístico, ecológico, ..., sem autorização da autoridade competente ou em desacordo com a concedida" com penas de multa e detenção de seis meses a um ano.

A poda ou supressão de espécies com princípios tóxicos foi abordada em 5 municípios: São Borja, Santa Cruz do Sul, São Paulo das Missões, Santo Ângelo e Giruá. Em São Borja, a abordagem apresentou-se mais ampla, onde no artigo 78 da Lei Municipal institui-se que "o corte ou poda de espécies portadoras de substâncias tóxicas ao homem e animais é permitido", porém não apresenta nominata das espécies que apresentam tais 
características para conhecimento da população, o que gera equívocos e constantes aumentos nas estatísticas de acidentes e intoxicações.

De acordo com o Instituto de Informações Toxicológicas do RS, registram-se anualmente 384 casos de intoxicações por plantas no estado. Um exemplo bastante elucidativo para a necessidade da lista de plantas tóxicas nas Legislações Municipais, seria a espécie popularmente denominada de Espirradeira (Nerium oleander) implantada largamente na arborização de praças, parques, vias públicas e jardins pela sua exuberante florada nas tonalidades rosa, púrpura e branca, tal planta apresenta princípios ditos cardiotóxicos como a oleandrina, que são altamente tóxicos, e apenas três sementes podem levar um homem adulto à morte (CERON et al., 2005; BARCELLOS, 2004).

Nos municípios de Santa Cruz do Sul, São Paulo das Missões, Santo Ângelo e Giruá a normatização da poda ou supressão se dá preferencialmente sobre a espécie Ligustro (Ligustrum sp.), que no Rio Grande do Sul é associada à incidência de problemas alergênicos denominados de "Polinose", e afetam principalmente a população urbana das cidades gaúchas, por ter efeito endêmico preferencial em latitudes maiores que $25^{\circ} \mathrm{S}$, e com condição climática de continentalidade (SBAI, 2003).

Porém, em especial, para os municípios da metade norte ou missões, a principal causa da Polinose não vem a ser o Pólen e a floração do Ligustro, mas sim pelo pólen de gramíneas forrageiras como o Azevém-anual (Lolium mutiflorum), Capim-inglês (Lolium perenne), Capim-lanudo (Holcus lanatus) cultivadas em larga escala para a alimentação do gado de leite, a presença de albuminas e proteínas globulinas predispõem a mucosa dos indivíduos a uma reação inflamatória, e estas espécies por apresentarem um caráter anemófilo, a dispersão do pólen das gramíneas é pelo vento, podendo ser disperso até mesmo a 90 km de distância, portanto o Ligustro serviria apenas de "natural primer", ou seja, um sensibilizador a ocorrências de alergias respiratórias (KURTZ, 1998).

Portanto, a total erradicação do Ligustro pela sua substituição gradativa nos centros urbanos da metade norte do estado, muito pouco contribuiria, para o aumento da doença, senão se reduzisse o emprego ou substituição destas forrageiras.

A reposição das árvores suprimidas no espaço urbano, dentro das Legislações urbanas, é a normativa que mais apresenta equívocos, pois conforme o Código Florestal Federal (Lei 4771/65) e Código Florestal Estadual (9.519/92), deve ser feita na proporção de 15 mudas plantadas para cada 01 árvore suprimida, seja em área urbana ou rural, e em municípios como São Borja que coloca que a reposição deverá ser feita na quantidade de 3 a 20 mudas para cada árvore suprimida, não informando os critérios para o mínimo de reposição (3 mudas para cada árvore suprimida), podendo gerar a depauperação do patrimônio arbóreo urbano do município. 


\section{CONCLUSÕES}

Com o presente estudo conclui-se que:

A legislação urbanística municipal pode e deve incentivar ao particular a conservação de áreas verdes em sua propriedade, assim como incentivar a sua criação e manutenção, possibilitando inclusive desconto no IPTU ao proprietário que constitui ou mantém áreas verdes no seu imóvel, esta atitude não foi observada nos municípios analisados no presente estudo.

A legislação federal contempla a construção de áreas verdes na área urbana, apesar de não ser totalmente eficiente e negligenciar a arborização das ruas, fato este referido e incentivado na legislação de alguns municípios analisados, como em Santo Ângelo. Porém o processo de conservação, preservação e valorização dos recursos naturais de modo a garantir a "qualidade de vida urbana" não ocorrem somente através da implantação de normas de conduta, tanto por parte dos órgãos públicos como dos indivíduos, ela só ocorre através da Educação Ambiental, atualmente um processo indispensável na sensibilização da sociedade visando detectar ações deletérias e preparando os seres humanos com uma visão ampla para pensarem na conservação visando as futuras gerações.

Recomenda-se a nível Federal a inclusão de um capítulo dentro do Estatuto das Cidades (Lei No 10.257/2001) sobre a arborização urbana, para que seja adotado como balizador para a elaboração de Legislações Municipais referentes a arborização, e finalmente possa-se obter a sustentabilidade e qualidade de vida dentro dos centros urbanos brasileiros.

\section{REFERÊNCIAS BIBLIOGRÁFICAS}

BACKES, P.; IRGANG, B. Árvores cultivadas no sul do Brasil: guia de identificação e interesse paisagístico das principais espécies exóticas. Porto Alegre: Editora da UFRGS, 204 p. 2004.

BARCELLOS, D.C. Plantas ornamentais tóxicas - remédios e venenos- da toxidez a letabilidade. Endereço: http://www.plantastoxicas.hpg.ig.com.br. Acesso: 06/02/2004. 32 p. BARREIROS, M. A.; ABIKO, A. K. Reflexões sobre o Parcelamento do Solo Urbano. (Boletim Técnico) Escola Politécnica da USP Departamento de Engenharia de Construção Civil São Paulo. São Paulo: EPUSP/PCC, 21p. 1998.

CARVALHO, P. F.; BRAGA, R. Perspectivas de Gestão Ambiental em Cidades Médias. Rio Claro: LPM-UNESP, 2001. p. 111 - 119. 
CERON, C. S; SILVEIRA, R. S; RECKZIEGEL, P.; FRÖHLICH, J.; POSADA, W.; KUNZ, V. T.;MANFRON, M. P. Seminário sobre plantas medicinais e tóxicas a alunos do município. In: XX JORNADA ACADÊMICA INTERGRADA DA UFSM. Santa Maria, 2005, p. 35.

GUIMARÃES, P. P. Configuração urbana: evolução, avaliação, planejamento e urbanização. São Paulo: Editora Pro Livros, 260 p., 2004.

KURTZ, J. A. T. A presença de polinose na região do planalto médio - Rio Grande do Sul. Revista Brasileira de Alergia e Imunopatologia. v. 21, n. 6, p. 196 - 202. 2005.

LERNER, J. O poder de transformação das cidades: um projeto para o Brasil. Ciência \& Ambiente, Santa Maria, RS, ano IV, n. 7, p. 43 - 54, jul./dez. 1993.

LISOVSKI, L.; ZAKREZEVSKI, S.B. O que é meio ambiente? In: ZAKREZEVSKI, S. B. A educação ambiental na escola: abordagens conceituais. Erechim: Edifapes, 128 p. 2003.

LOMBARDO, M. A. Vegetação e clima. In: III ENCONTRO NACIONAL SOBRE ARBORIZAÇÃO URBANA. Anais... Curitiba, PR. 1990. 01 -13.

LORENZI, H. Árvores Brasileiras: manual de identificação e cultivo de plantas arbóreas nativas do Brasil. Nova Odessa: Editora Plantarum, 352 p. 1992.

MALAVASI, U. C.; MALAVASI, M. M. Avaliação da arborização urbana pelos residentes estudo de caso em Marechal Cândido Rondon, Paraná. Revista Ciência Florestal. v.11, n. 1, 2001. p. $189-193$.

MENEGAT, R.; PORTO, M. L.; CARRARO, C. C.; FERNANDES, L. A. D. Atlas ambiental de Porto Alegre. Porto Alegre: Editora UFRGS. 228 p. 1998.

MINISTÉRIO DAS CIDADES. Estatuto das Cidades (Lei n. 10.257/2001) Disponível em: http://www.cidades.gov.br. Acessado em: 23/11/2006.

MINISTÉRIO DA JUSTIÇA. Constituição Federal do Brasil. Disponível em: http://www.mj.gov.br/ccivil. Acessado em: 23/11/2006.

MINISTÉRIO DA JUSTIÇA. Código de Defesa do Consumidor (Lei n. 8.078/90) Disponível em: http://www.mj.gov.br. Acessado em: 23/11/2006.

MINISTÉRIO DA JUSTIÇA. Lei de Acesso a Informações Ambientais (Lei $\mathbf{n}$. 10.650/2003) Disponível em: http://www.mj.gov.br/ccivil. Acessado em: 23/11/2006.

MINISTÉRIO DA JUSTIÇA. Lei de Parcelamento e uso do solo (Lei n. 6.766/79) Disponível em: http://www.mj.gov.br/ccivil. Acessado em: 23/11/2006.

MNISTÉRIO DO MEIO AMBIENTE. Código Florestal Federal (Lei n. 4.771/65) Disponível em: http://www.mma.gov.br. Acessado em: 23/11/2006.

MNISTÉRIO DO MEIO AMBIENTE. Política Nacional do Meio Ambiente (Lei n. 6938/81) Disponível em: http://www.mma.gov.br. Acessado em: 23/11/2006.

MNISTÉRIO DO MEIO AMBIENTE. Lei de Crimes ambientais (Lei $\mathbf{n} . \mathbf{9 . 6 0 5 / 9 8 )}$ Disponível em: http://www.mma.gov.br. Acessado em: 23/11/2006. 
PAIVA, H. N.; GONÇALVES, W. Florestas urbanas: planejamento para melhoria da qualidade de vida. Viçosa: Editora Fácil, 2002. 180 p.

PREFEITURA MUNICIPAL DE SÃO BORJA. Dados sobre o município. Disponível em: http://www.saoborja.rs.gov.br. Acessado em: 30/11/2006.

PREFEITURA MUNICIPAL DE SANTA CRUZ DO SUL. Dados sobre o município. Disponível em: http://www.pmscs.rs.gov.br. Acessado em: 30/11/2006.

PREFEITURA MUNICIPAL DE QUINZE DE NOVEMBRO. Dados sobre o município. Disponível em: http://www.quinze.rs.gov.br. Acessado em: 30/11/2006.

PREFEITURA MUNICIPAL DE SÃO PAULO DAS MISSÕES. Dados sobre o município. Disponível em: http://www.portalmunicipal.org.br. Acessado em: 30/11/2006.

PREFEITURA MUNICIPAL DE SANTO ÂNGELO. Dados sobre o município. Disponível em: http://www.santoangelo.rs.gov.br. Acessado em: 30/11/2006.

PREFEITURA MUNICIPAL DE GIRUÁ. Dados sobre o município. Disponível em: http://www.caxias.rs.gov.br. Acessado em: 30/11/2006.

PREFEITURA MUNICIPAL DE PELOTAS. Dados sobre o município. Disponível em: http://www.pmgirua.com.br. Acessado em: 30/11/2006.

PREFEITURA MUNICIPAL DE NONOAÍ. Dados sobre o município. Disponível em: http://www.pelotas.rs.gov.br. Acessado em: 30/11/2006.

PREFEITURA MUNICIPAL DE URUGUAIANA. Dados sobre o município. Disponível em: http://www.uruguaiana.rs.gov.br. Acessado em: 30/11/2006.

SBAI, SOCIEDADE BRASILEIRA DE ALERGIA E IMUNOLOGIA. Polinose. Endereço: http://www.sbai.org.br. Acessado em: 03/05/2006. 8 p.

SEMA, SECRETARIA ESTADUAL DO MEIO AMBIENTE. Código Florestal Estadual (Lei n. 9.519/92) Disponível em: http://www.sema.rs.gov.br. Acessado em: 23/11/2006.

SILVA, D. F.; BORTOLETO, S. Uso de indicadores de diversidade na definição de planos de manejo da arborização viária de águas do São Pedro - SP. Revista Árvore, v. 29, n. 6, p. $973-982,2005$.

SIRVINSKAS, L. P. Arborização urbana e meio ambiente - aspectos jurídicos. Disponível em: http://www.mp.sp.gov.br. Acessado em: 23/09/2003.

STRINGHETA, A. C. O. Arborização Urbana no Brasil. Ação Ambiental, Viçosa, MG, ano VIII, n. 33, 2005. p. $9-11$.

TEIXEIRA, I. F.; ZAMBERLAN, N. R. S.; BALEST, S. S. PADOIN, V.; SALDANHA, C. W.; SANTANA, C. A. Arborização de ruas x espaço urbano: caracterização quantitativa. In: CONGRESSO FLORESTAL ESTADUAL DO RIO GRANDE DO SUL. Anais... Nova Prata: Prefeitura Municipal de Nova Prata/FATEC, 2003. p. 80 - 88.

WOLF, K. L. O valor econômico e social das florestas urbanas. Revista Agricultura Urbana, n. 13, 2005, p. 2 - 9. Disponível em: Acessado em: 28/06/2006. 